\title{
Correction to: The prevalence and profile of autism in individuals born preterm: a systematic review and meta-analysis
}

Catherine Laverty $^{1 *}$, Andrew Surtees ${ }^{1,2}$, Rory O'Sullivan ${ }^{3}$, Daniel Sutherland ${ }^{1}$, Christopher Jones ${ }^{1}$ and Caroline Richards ${ }^{1}$

\section{Correction to: J Neurodev Disord 13, 41 (2021)}

https://doi.org/10.1186/s11689-021-09382-1

In the original publication of this article [1] the following data points were missing from Table 1 (pages $6 \& 7$ ) due to a word processing error.

a. Mir et al., 2020 - Quality weightings of 'Autism - 2' 'Sample Identification - 1' 'Design - 2'.

b. Vermeirsch et al., 2020 - Quality weightings of 'Autism - 2' 'Sample Identification - 1' 'Design.

The correct Table 1 is shown in the next pages. Two author's affiliations have been amended to be 'School of Psychology, University of Birmingham, Birmingham, B15 2TT, UK'. The original article has been corrected.

\author{
Reference \\ 1. Laverty C, Surtees A, O'Sullivan R, Sutherland D, Jones C, Richards C. The \\ prevalence and profile of autism in individuals born preterm: a systematic \\ review and meta-analysis. J Neurodev Disord. 2021;13(1):1-12.
}

\section{Author details}

${ }^{1}$ School of Psychology, University of Birmingham, Birmingham, B15 2TT, UK. ${ }^{2}$ Forward Thinking Birmingham, Birmingham Women's and Children's NHS Foundation Trust, Birmingham, UK. ${ }^{3}$ School of Psychology, Loughborough University, Loughborough LE11 3TU, UK.

Published online: 24 December 2021 to the material. If material is not included in the article's Creative Commons licence and your intended use is not permitted by statutory regulation or exceeds the permitted use, you will need to obtain permission directly from the copyright holder. To view a copy of this licence, visit http://creativecommons.org/licenses/by/4.0/. The Creative Commons Public Domain Dedication waiver (http://creativeco mmons.org/publicdomain/zero/1.0/) applies to the data made available in this article, unless otherwise stated in a credit line to the data. 


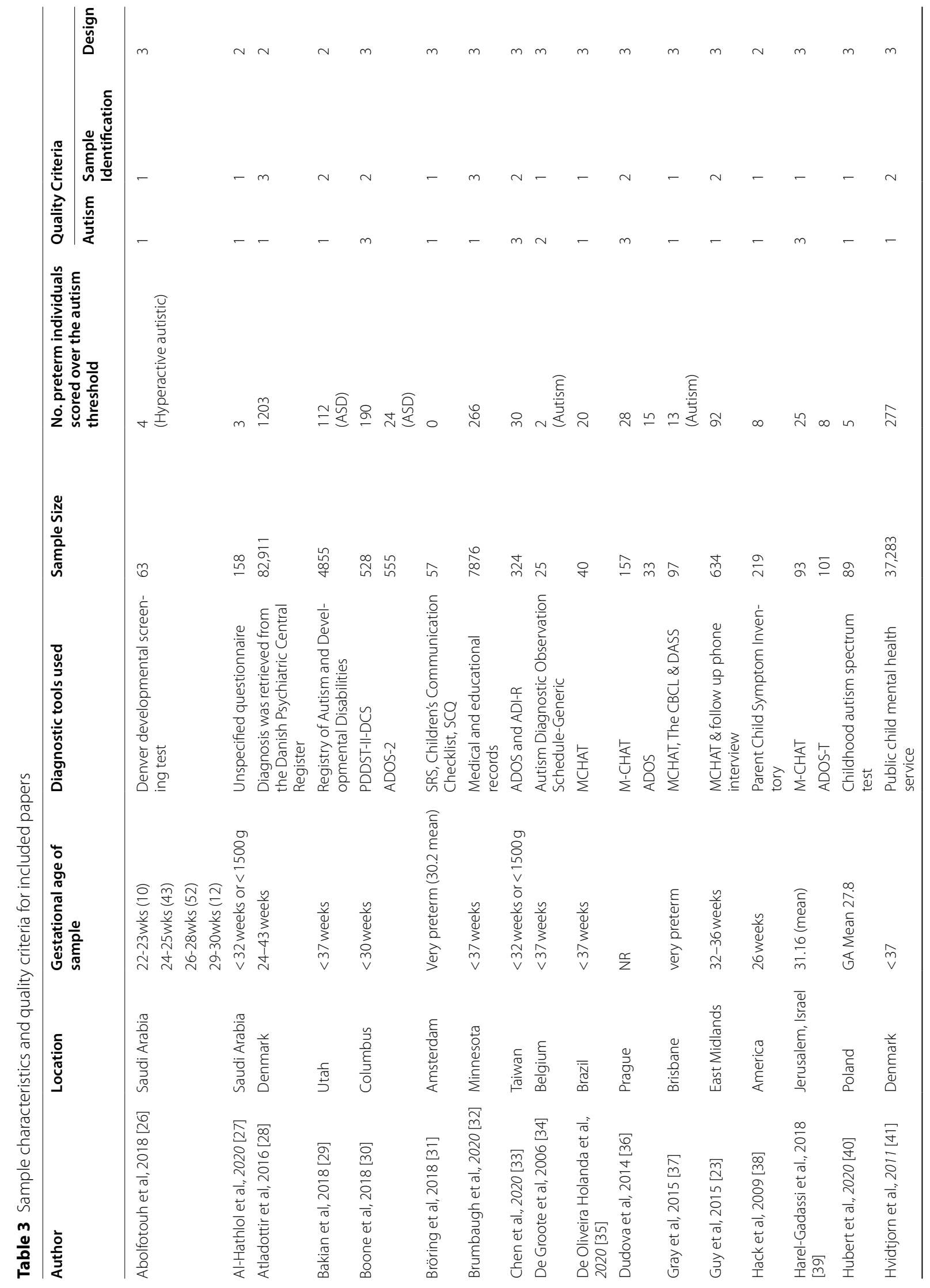




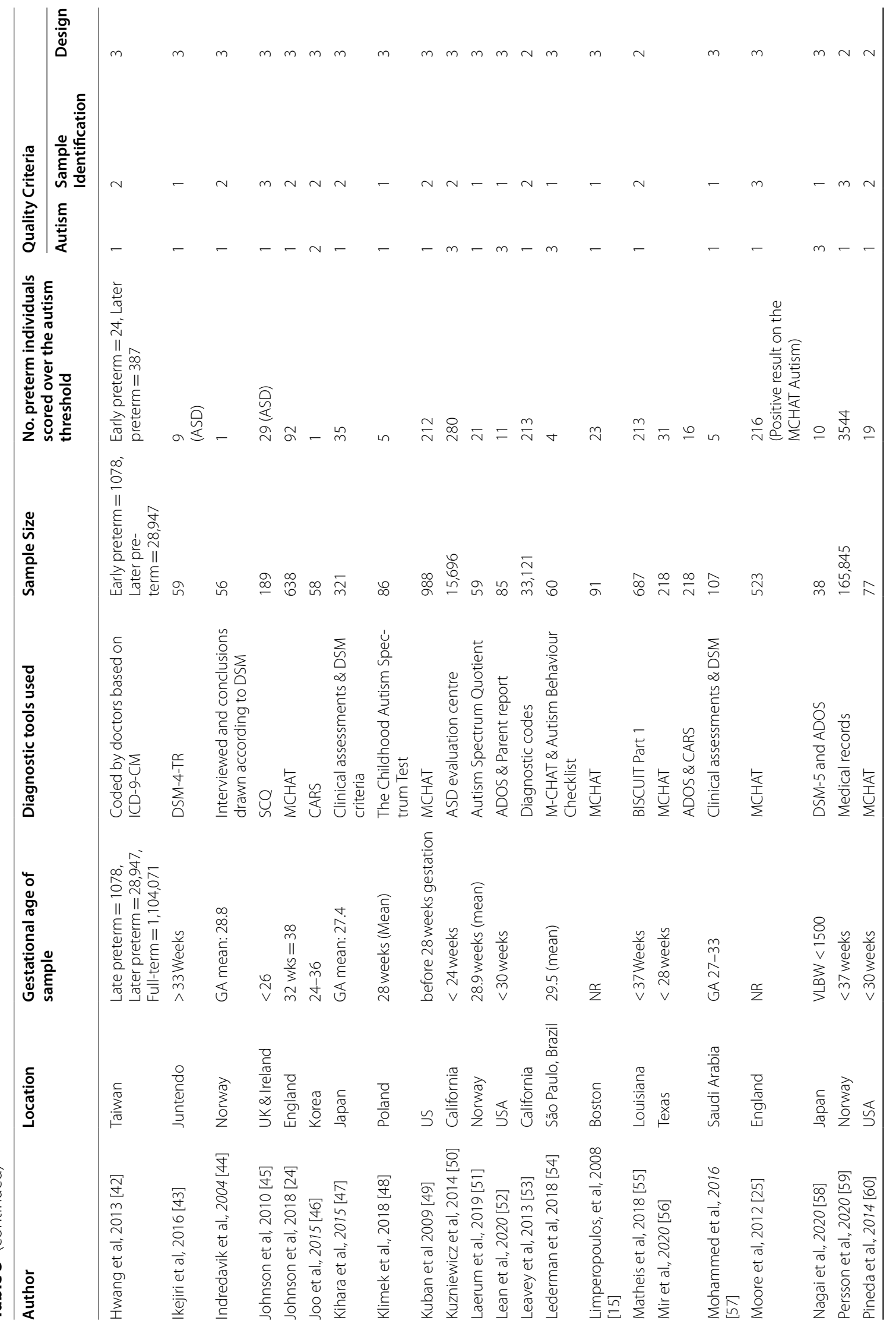




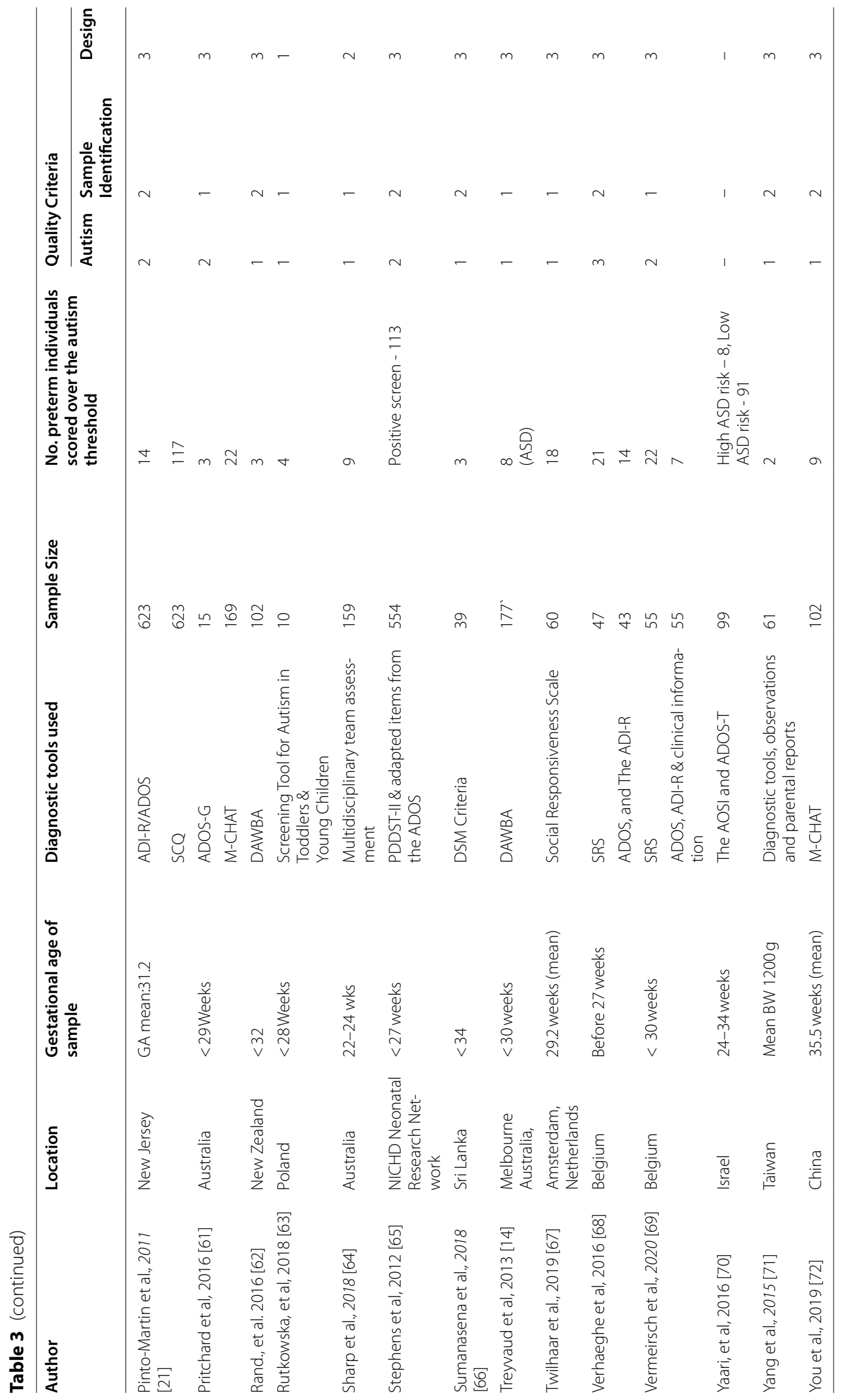

